\title{
Participation as an Effective Means of Enhancing Farmers' Sense of Ownership Towards Forest Management: The Case of Jello Forest, West Hararghe Zone, Oromia Regional State
}

\author{
Mufedei Mohammed Kasim \\ Department of Environmental Science, Oda Bultum University, Chiro, Ethiopia \\ PO. Box, 226 Chiro, Ethiopia
}

\begin{abstract}
Alienating forest dependent communities from forest by depriving them of the right to use forest resource is what widely accepted over recent years as a major factor in conditioning local communities to develop feelings of hostility towards the forest; and push them to destroy the forest resource irresponsibly. This consideration was lied the foundation for new development in forest management known as participatory forest management (PFM).This form of forest management through local participation is a phenomenon that emerged over recent decades as a remedial measure to the old (top down) form of forest management. One of the core concepts in this Participatory forest management (PFM) is improving local community's sense of ownership toward the forest by empowering them as both developer and beneficiaries of forest resources. Taking local participation as fundamental principle of PFM approach, this research was under taken on Jello forest with the objective of studying local communities' participation, attitude towards the new approach (PFM) and improvements in their sense of ownership toward the forest. A total of 172 sampled respondents were randomly selected from both non-PFM and PFM member households. Data were collected from sampled households using Household survey questionnaire, key informant interview and focus group discussion. Qualitative data were analyzed using content and discourse analyses; whereas quantitative data were analyzed by descriptive statistics using R-statistical software. Accordingly the result of household survey, focus group discussion and key informant interview were revealed that local communities participation in forest management have improved under the newly introduced forest management system (PFM). The study further revealed that local communities have positive attitude towards PFM and also their sense of ownership toward the forest has significantly improved. About $70 \%$ of nonPFM and $85 \%$ of PFM members were strongly agreed that the establishment of PFM has improved communities' participation in forest management. Based on the findings of this study it could be concluded that PFM is effective in improving local community's participation and sense of ownership towards the forest.
\end{abstract}

Keywords: Participatory Forest management, Sense of Ownership, participation, Sustainable development, Jello Forest.

DOI: $10.7176 /$ JAAS/59-01

Publication date: December $31^{\text {st }} 2019$

\section{INTRODUCTION}

The estimation made by Forest and Agricultural Organization of UN report (2012), states that, the age of deforestation goes back as early as human civilization. Current assessment indicates that, for over the past 25 years (i.e. 1990-2015) alone, our world has experienced the net loss of some 129 million ha of forests (natural and planted) representing a total area about the size of South Africa (FAO, 2015). The biggest proportion of forest area loss during this time has occurred in the tropics, particularly in South America and Africa (FAO, 2015).

Being one of the developing countries in Africa, Ethiopia is exceptionally rich in cultural and biological diversity. However, this rich cultural and natural heritage is threatened (Gatz Weiler, 2007). Even though, Ethiopia's deforestation rate is about average when compared to other east African countries, deforestation rates and decline in forest conservation in region are the second largest in the African continent (Gatz Weiler, 2007). Historical source indicates that about 42 million ha or equivalent of 35\% of Ethiopia's total land area had been covered with forests (Reusing, 2000). The estimate further indicates that, in the early 1950, the remaining forest covered 19 million ha or $15 \%$ of the land area. In the early 1980 , coverage was reported at $3.6 \%$ and in the 1989 it was estimated to be only 2.7\% (Mulugeta Lemenih and Melaku Bekele, 2008).

In accounts of the increasing human and livestock population, the demand for forest products and forest land for the expansion of farm and grazing lands has increased in Ethiopia over the last decades (MoARD \& WB, 2007).This coupled with the ineffective forest management efforts over the past (Badege Bishaw, 2001), has resulted in over exploitation of forest resources in Ethiopia.

It is obvious that the importance of forest resources to human life and the degradation resulting of human intervention brings the issue of forest management into the fore front. Accordingly the continued deforestation and forest degradation in Ethiopia, despite the long time government's effort to deal with the problem, 
stimulated the concern to look for alternative means of forest management. The old approach (top-down) that sought to halt forest exploitation through expropriation of forest dependent communities and by enacting laws to reduce human impacts on forests, proved itself disincentive in terms of managing resource productively and sustainably. Amogne Asfaw (2014) stated that, the most negative environmental impact in Ethiopia, during the Derge regime (1974-1991), came from policy and regulatory interventions that cumulatively eroded the rights of individuals and communities to use and manage their own resources. The old approach that was mainly focused on prohibitive rules, that denies access rights of the local people, came to erode the age old customary practices which have maintained forest resources (Tsegaye Gobeze, 2009). As the result, local peoples were conditioned to develop a feeling of hostility that eroded sense of ownership toward the forests. This situation let the forests remain without an owner, given the absence of formal and informal institution that could guard forests from various illegal activities.

As an alternative means to deal with the shortcoming of the Top-down approach, in which government plays the central role, the Bottom-up approach emerged, in which local communities play central role (Winberg, 2010; Alemayehu Negassa et al, 2015). PFM is one of these participatory and sustainable use approaches which have demonstrated magnificent results in protecting forest resources and contributing to the livelihood means of the local people (Tsegaye Gobeze, 2009). The central premise of PFM approach is that, local communities who live in close proximity to a forest possess an inherent capacity, knowledge and interest to govern their resources properly (Ostrom 1990; Alemayehu Negassa et al 2015). Accordingly in PFM under the terms of agreement between government and local communities, forest management responsibilities and use rights will be granted to local communities with technical support being provided from government and non-government (NGOs) stakeholders (Alemayehu Negassa et al, 2015). Similarly PFM was introduced in to Ethiopia through NGOs and government agencies to deal with the persistent problems of deforestation and to deliver better social and economic outcomes compared with the former centralized command-and-control resource management approach (FARM-Africa and SOS'Sahel, 2007; Yemiru, 2011).

In 2007, Oromia regional state has established forest enterprises with a supervising agency, and restructured it in to Oromia Forest and Wildlife Enterprise (OFWE) since 2009. OFWE manages all state forests and many natural forests through PFM arrangement in Oromia. Accordingly through its sub-branch office of Hararge zone and in cooperation with nongovernmental organization (i.e. AMBERO-GITEC/GTZ) OFWE initiated PFM project in Jello forest with the intention to halt deforestation through devolution of power between government (forestry department) and local communities and thereby empowering local communities; boosting their sense of ownership to manage and use forests responsibly. Given the establishment of PFM at Jello forest as sustainable means to deal between poverty alleviation and forest conservation; by enhancing local communities' participation and improving their sense of ownership towards the forest; a study can help to strengthen the approach by elaborating over issues pertaining to the success and failure of the project. To this end, this research tries to assess the effectiveness of participatory forest management (PFM) in changing local communities' sense of ownership toward the forest as opposed to pre intervention period. To our knowledge no research has been carried out so far under the current title and this research tries to fill this gap and there by tries to contribute to the existing body of knowledge.

\section{MATERIALS AND METHOD}

\subsection{Description of the Study Area}

\subsubsection{Location}

The study was conduct on Jello Forest which is situated in Jello-Muktar State Forest Priority Area at about $332 \mathrm{kms}$ southeast of Addis Ababa. Geographically located at $8^{\circ} 55^{\prime} \mathrm{N}$ latitude and $40^{\circ} 50^{\prime} \mathrm{E}-40^{\circ} 51^{\prime} \mathrm{E}$ longitude. The forest shares boundaries in North and East with Chiro Woreda, in the South-east with Gemechis woreda and in the west with Oda Bultum woreda (Jello forest project management plan, 2009). 
Fig. 1 Map of the study area

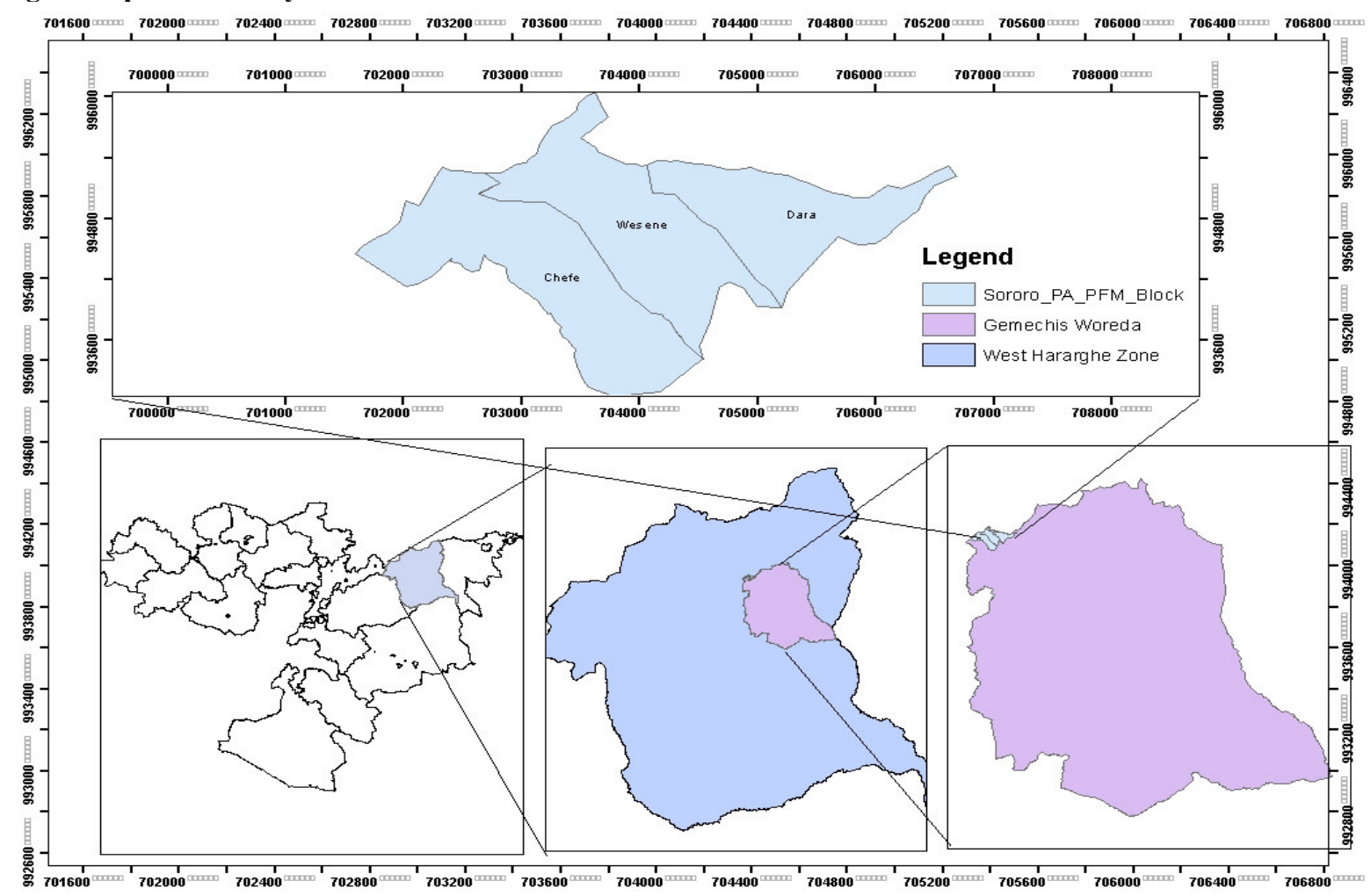

\subsubsection{Climate}

Jello forest area is found at an altitude ranging between 2000 and 3074 m.a.s.l. It has a subtropical climate condition with mean annual temperature of $15^{\circ} \mathrm{C}$ and mean rainfall of $1220 \mathrm{~mm}$. The length of growing period ranges from 210-270 days (MOA/FAO/UNDP, 1983). The rain fall pattern is bimodal, with the short rainy season from February to March and the main rainy season from March to July (West Hararge ARDO, 2013).

\subsubsection{Soil}

The soil of the study aria is mainly made up of basaltic rock formation that resulted from the formation of two main soil types. On the flat plateau and wide valley bottom, there are heavy clay soils-which is black cotton soil and on the slopes reddish brown loam which are combisols (Jello forest project management plan, 2009).

\subsubsection{Vegetation}

The forest in the study is mainly characterised by dry afromontain forest; and covering an area of around 7820 ha. Some of the characteristic tree and shrub species include: Podocarpus falcatus, Juniperus excels, Vernonia spp., Rosa abyssinica, Bersema abyssinica, Dodonaea augostifolia, Haginia abyssinica and others (Jello forest project management plan 2009; OFWEHBO, 2014).

\subsection{Sampling Method}

Sample size was determined by using sample size determination formula $\mathbf{n}=\mathbf{N} /\left(\mathbf{1}+\mathbf{N}^{*} \mathbf{e}^{\mathbf{2}}\right)$ adopted from Yamane (1969). In this case, $\mathbf{n}$ stands for sample size, $\mathbf{N}$ for total households (HHs) and e represent level of precision. With $90 \%$ confidence level and an error limit of 10\%. Accordingly, 86 PFM member households have been selected.

The sampled households were randomly selected by using PFM group members list from the three PFM blocks (Chefe, Wesene and Gende-dara) found in Sororo kebele and an equivalent number of households from non-PFM were randomly selected from the same kebele.

\subsection{Methods of Data Collection}

\subsubsection{Data Source}

For this research purpose, both primary and secondary data were used. Primary data was collected through key informant interview, focus group discussion and household survey. The source of secondary data include published and unpublished material references such as: books, journals, project reports and maps.

\subsubsection{Data Collection tools}

Key Informants: Key informants who have deep knowledge of their locality were selected through snowball methods and the information collected was used as an input for group discussion and for developing 
questionnaire for households' survey. Those key informants were forestry expert at woreda level, chair person of FUG cooperatives, community leader and female representative.

Focus Group Discussion: The participant for focus group discussions were selected on the basis of their knowledge of PFM activities and position in the PFM cooperative. Accordingly, four focus group discussions with number of participants ranging from 8 persons to 12 persons were undertaken. Within the three focus group discussion held in each three PFM blocks, Participants were both female and male members of PFM; and one focus group discussion is only composed of female members of PFM. Female group discussion was undertaken to discover effect of PFM on women's participation. PFM participant members list were used to select respondents. The collected data was mainly used to assess the effect of PFM on community's level of participation in forest management activities and sense of ownership towards the forest.

Household Survey: A total 172 households both from PFM blocks and non-PFM members were used for the survey. Socio-economic data were collected through questionnaire composed of both closed and open ended question divided into three sections and six subsections ingeneral. Each subsection has 5 to 16 closed ended questions, based on Likert-Scale model, in addition with one or two open ended questions to get the context. The questionnaire was pre-tested to check wither it is easy to be understood by the respondents and capable of collecting the required data. Furthermore, the questionnaire was translated into local language Afan Oromo and it was presented to the respondents verbally (with the consideration that majority of the farmers cannot read and write). In order to facilitate this, three enumerators were drawn from the locality with minimal educational level of $10^{\text {th }}$ grade and were trained. The collected data was used to study attitude towards PFM and its ecological effects.

\subsection{Data Analysis}

The responses of the key informants and records of Focus Group Discussions were coded and analyzed using content and discourse analysis methods. Accordingly, relevant themes and concepts were identified and summarized.

The household survey data were analysed using descriptive statistical analyses, presented using tables, bar graphs. Supporting tool for the analyses was R statistical software.

\section{Result and Discussion}

\subsection{Socio-economic characteristics of respondents}

The results of this study indicate that, household size of PFM members and non-PFM ranges from 2-11 and 3-10 members respectively. Mean household size recorded for PFM and non-PFM households were similar average household being 6.36 and 6.29 members respectively. The mean household sizes of participants in adults age class were slightly larger compared to those of the young age class. For households in the young age class mean size was 5.14 and 4.8 members for PFM and non-PFM respectively, while for households in adult age class households mean size of PFM the mean household size were 6.7 and 7.0 members for PFM households and noPFM households respectively (Table 3.1).

Table 3.1: Household size of different age classes and corresponding farm land holdings

\begin{tabular}{|c|c|c|c|c|c|c|}
\hline \multirow[b]{2}{*}{ Age-class years } & \multicolumn{3}{|c|}{ PFM households $(n=86)$} & \multicolumn{3}{|c|}{ Non-PFM households $(n=86)$} \\
\hline & description & family size & $\begin{array}{l}\text { Landholding } \\
\text { (ha) }\end{array}$ & description & family size & $\begin{array}{l}\text { Landholding } \\
\text { (ha) }\end{array}$ \\
\hline \multirow{3}{*}{$\begin{array}{l}\text { Young } \\
18-30\end{array}$} & Mean & 5.14 & 0.33 & Mean & 4.8 & 1 \\
\hline & minimum & 2 & 0.25 & minimum & 3 & 1 \\
\hline & maximum & 8 & 0.5 & maximum & 8 & 1 \\
\hline \multirow{3}{*}{$\begin{array}{l}\text { Adult } \\
31-55\end{array}$} & Mean & 6.7 & 0.37 & Mean & 7 & 2.05 \\
\hline & minimum & 4 & 0.25 & minimum & 4 & 1 \\
\hline & maximum & 11 & 1.00 & maximum & 10 & 3 \\
\hline \multirow{3}{*}{$\begin{array}{l}\text { Old } \\
>55 \text { years }\end{array}$} & Mean & - & - & Mean & - & - \\
\hline & minimum & - & - & minimum & - & - \\
\hline & maximum & - & - & maximum & - & - \\
\hline \multirow[t]{3}{*}{ Total } & Mean & 6.36 & 0.31 & Mean & 6.29 & 1.68 \\
\hline & minimum & 2 & 0.25 & minimum & 3 & 1 \\
\hline & maximum & 11 & 1.00 & maximum & 10 & 3 \\
\hline
\end{tabular}

The result of this study also indicates that the overall landholding of sampled households range from 0.25 ha of land to $3 \mathrm{ha}$; and the overall mean of farm land owned by the respondents was 0.95 ha. However, there was a difference between the mean number of farm land owned by PFM and non-PFM households. PFM households had 0.31 ha farm land on average while non-PFM households had 1.68 ha farm land on average. Accordingly non-PFM members owned more hectares of farm lands compared to PFM members (Table 3.1). Similarly an 
interview with forest experts revealed that, land holding was one of the major criteria for household enrolment into PFM. Difference in landholding was also detected between young respondents of PFM households and nonPFM households. The mean landholding for young age class respondents of PFM and non-PFM households were 0.33 and 1 ha respectively. Furthermore, the result indicates that the average landholding for adult age class respondents of PFM and non-PFM members was different. Accordingly the mean landholding for adult age class of both PFM and non-PFM were 0.37 and 2.05 ha respectively (Table 3.1). This indicates that besides the shortage of farm land in the area in general there are also high variations in land ownership among locals especially between PFM and no-PFM members.

\subsection{Improvement in the Level of Participation in Forest Management}

As the data acquired through focus group discussion indicates, the introduction of PFM has enhanced local people's participation in forest management. According to focus group discussion, prior to the PFM introduction there were no significant efforts that have been under taken to manage the forest from the side of society. The area was highly degraded as the result of forest clearing in search for: productive cultivation lands, timber, fire wood, farm implements, house construction, etc. People in the area were in high competition to exploit the forest rather than responsibly managing as the forest was used to be open access. Prior to PFM introduction, responsibility to manage and develop forest was belong to the state accordance with the law but practically forest was open to all kinds of exploitation. People used to seize forest lands as a reserve for future use owing to future uncertainty in case forest is open access for all and also to meet their households need for food security. Fire wood were also harvested for own consumption and for sale. In some case firewood were also harvested and kept for feature use. During the mass mobilization for tree plantation program initiated by local government, peoples used to participate unwillingly and they hardly look after the planted tree to grow up afterwards. Thus, before the introduction of PFM local communities hardly partake in forest management rather they often participated unconditionally in forest exploitation.

However, the situation has changed after responsibilities to manage the forest have been conferred to the local societies through signed agreements. This is because, with the introduction of PFM local societies granted access rights to forest products through signed agreement and their demands for forest ownership were maintained. PFM empowered local people as a custodian and developer of the forest resources. It enabled them to organize themselves and enhance their participation in decision making regarding the management of the forest resources. Thus, free access to the forest has been regulated well than before. According to focus group discussion, members of PFM actively participate in the meetings, plantation campaign, guarding the forest from encroachment and by abstaining themselves from undertaking any illegal activities in the delimited area of the forest. They also actively participate in nursery management and forest protection activities. Firewood collected for sale also declined significantly as was found out during discussions with women groups. Thus, the adoption of PFM scheme in Jello forest was able to enhance local community's level of participation in forest management as compared to pre- PFM establishment situations in which "tragedy of the common" took place.

\subsection{Sense of Ownership towards the Forest}

Sense of ownership refers to people's willingness to carry the responsibility to manage the forest as the owner of the resource. Melaku Bekele, (2003) identified in his study that, the lack of stability of rural institutions and subsequent confusions over tenure and access rights have affected people's willingness to invest on land management practices and on tree planting. Furthermore Tsegaye Gobeze et al, (2009) also stated that, without the legal recognition of the right to use forest products, local people have neither the interest nor the courage in protecting and developing forests. Such systems would rather generate an incentive structure that force locals to irresponsibly exploit forests. Furthermore, Nygren (2005) stated that with decentralized natural resource management, local people may feel a greater sense of ownership. In this regard this study also revealed similar results. According to the focus group discussion and also key informant the adoption of PFM has enhanced local people's sense of ownership towards the forest. The following is the statements from chair person of FUG cooperatives

“....before the establishment of PFM local peoples used to kill wild animals without due regard. They were not guaranteed that abstaining from hunting animals will benefit them in some way or another. However, after the establishment of PFM local communities were much more benefiting from the forest as they achieve a lot of money through controlled hunting. Now the farmers refrained from hunting as the controlled hunting provides them with much better benefit."

As it is clear from the above statements PFM able to enhance local people's participation in forest conservation as it provides a promising benefit in return for their contribution. This is to mean that, the establishment of PFM has improved people's interest and courage to protect the forest as it grants tenure rights over forest resources. According to focus group discussion, before PFM local peoples used to cut the trees from forest and leave it without replacing. Since the local societies have been alienated from the ownership right over 
forest and the forest was also remained without formal and informal institution that could guard forests against all sort of exploitation, there has been no incentive for the society to actively contribute in the forest management activities. The respondents further stated that, with the arrangement of PFM in the area local societies began to achieve various kinds of products from the forest for own consumption and for cash income generation such as honey, pasture and controlled hunting. These were also verified through field observations as it is evident from the following figure (3.1 and 3.2).

Fig 3.1: Fodder (hey) for Livestock
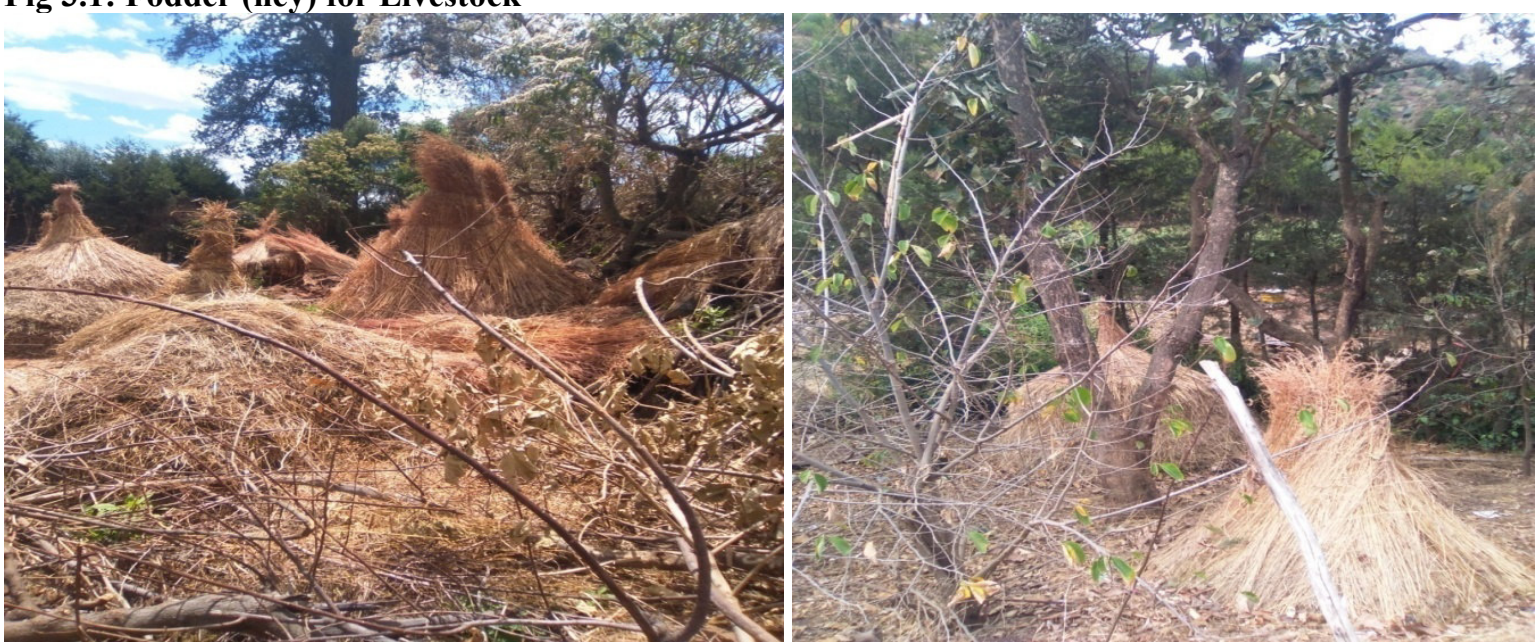

Fig 3.2: Bee keeping and Ox fattening

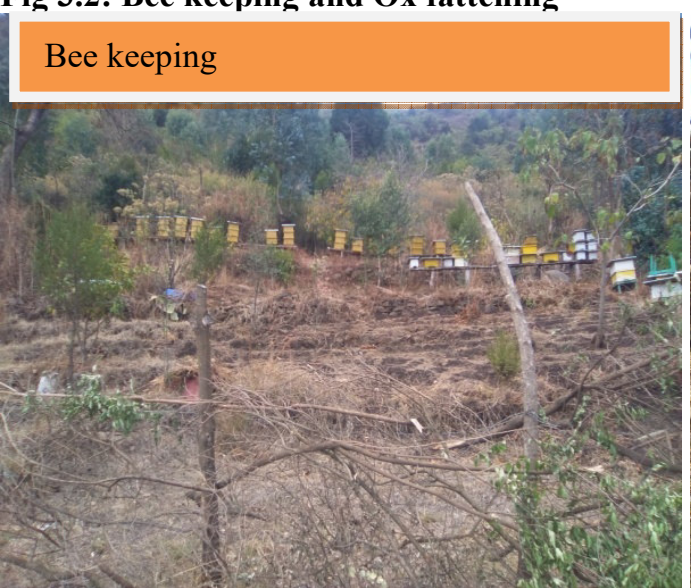

Ox fattening through cut and carry system

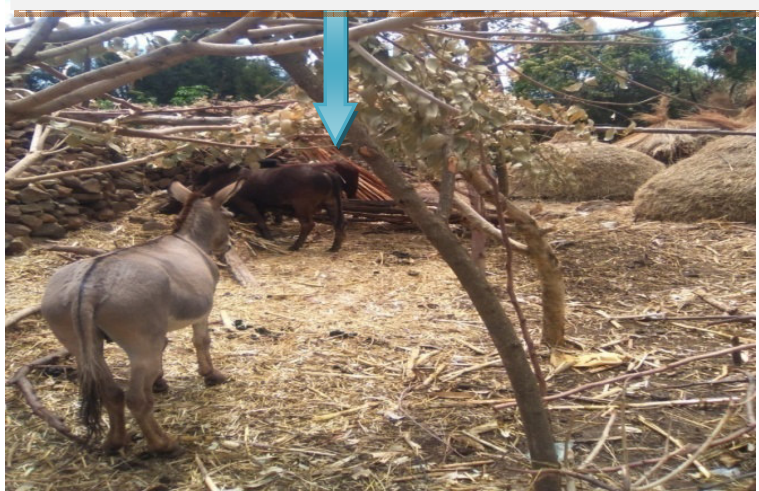

One of the project members' also stated that currently they came to consider forest as their only farm land. His full statements are quoted as follows:

"...unlike before-PFM now the forest has many things to provide us with. We can get sufficient fodder for our livestock, firewood and honey. We are supplying milk for the market in high amount than ever. We reached the stage to realize that conserving the forest has great benefit than it costs. We have started to see forest as our own farm land to produce from."

As it is also evident from the above quotation from the respondents, the establishment of PFM in the Jello forest enhanced local communities' sense of ownership towards the forest as compared to pre-PFM.

As the result indicates about $85 \%$ and $10 \%$ of the respondent from the PFM household's were answered strongly agree and agree respectively that PFM has improved sense of ownership towards the forest; while about $70 \%$ and $30 \%$ of the non PFM households were answered strongly agree and agree that PFM has improved sense of ownership. Only 5\% of the respondents from PFM members were disagreed that the establishments of PFM has improved peoples sense of ownership towards the forest. From both PFM and non-PFM members about $67 \%$ and $73 \%$ respectively were agreed that PFM has improved the livelihood of PFM participant households while $33 \%$ and $14 \%$ of PFM and non-PFM households respectively were disagreed.

\section{Conclusion and Recommendation}

\subsection{Conclusion}

Depending on the findings of this research, it is plausible to conclude that the establishment of Participatory forest management system can positively influence participation of local communities in forest management and 
there by improve their sense of ownership towards forest resource which was previously faded out due to the centralized form of forest management system. The establishment of PFM has also substantial importance in enhancing local community's sense of ownership towards the forest and forest resources as peoples are privileged as both developer and beneficiary of the forest resources.

Generally it could be concluded that PFM in Jello forest is effective in terms of enhancing local community's level of participation in forest management and improving sense of ownership towards forest.

\subsection{Recommendation}

Based on the finding of the study, it could be recommended that, if this new form of forest management is scaled up in other forest areas of the country it will help to engender favourable attitude toward forest conservation by enhancing local community's sense of ownership toward the forest. It is also helpful if this new approach is extended to neighbouring forests like Muktar Mountain forest.

\section{Reference}

Ajzen and Fishbein, 1977, Attitude-Behavior Relations Theoretical Analysis and Review of Empirical Research. Psychological Bulletin, 84(5), 888-918.

Ajzen, 2001, Nature and operation of attitudes. Annual Review of Psychology, 52(27-58

Alemayehu Negassa et al 2015, Performance of participatory forest management in Ethiopia: institutional arrangement versus local practices, Critical Policy Studies, Routledge

Ambastha et al, 2007, Resource dependence and attitudes of local people toward conservation of Kabartal wetland: a case study from the Indo-Gangetic plains. Wetlands Ecology and Management, 15(4), 287-302

Amogne Asfaw, 2014, forest resource management systems in Ethiopia: historical perspective, international journal of bio diversity and conservation, Vol, 6(2), pp 121-131

Badage Bishaw, 2001, deforestation and land degradation on the Ethiopian high lands: a strategy for physical recovery, Ethiopian tree fund foundation (ETFF)

Campbell et al, 2009, Building future scenarios and uncovering persisting challenges of participatory forest management in Chilimo Forest, Central Ethiopia, Journal of Environmental Management, 90(2), 1004-1013

FAO, 2012, State of the World's Forests, Rome, Italy

FAO, 2015, Assessment of Forests and Carbon stocks 1990-2015, Forestry paper 147, Rome

Farm-Africa and SOS'Sahel, 2007, the key stapes in establishing participatory forest management: a field manual to guide practitioner in Ethiopia, Best Practice series No.1, Addis Ababa, Ethiopia.

Gatz Weiler, 2007, Deforestation of Ethiopia's Afromontane rain forest, (ZEF) Bonn University, German

Jello forest project management plan, 2009, Chiro (AsebeTeferi), Ethiopia

MOA/FAO/UNDP, 1983, Generalized Agro climatic Map, Ethiopia, Assistance to Land Use Planning Project, FAO/UNDP-ETH/78/003, Addis Ababa, Ethiopia of Forest and Protected Area Management, 73-107.

MoARD\& WB, 2007, Ethiopia: Thematic Papers on Land degradation in Ethiopia, Ministry of Agriculture and Rural Development and World Bank, Addis Ababa, Ethiopia

Mulugeta Lemenih and Melaku Bekele, 2008, Participatory Forest Management Best Practices Lesson Learnt and Challenges Encountered: The Ethiopian and Tanzanian Experience

Ostrom, 1990, Governing the Commons: the Evaluations of Institutions for Collective Actions, Cambridge University Press

Reusing, 2000, Change Detection of Natural High Forests in Ethiopia Using Remote Sensing and GIS Techniques, International Archives of Photogrammetry and Remote Sensing, Vol. XXXIII, Part B7, pp 1253-1258, Amsterdam.

Solomon Tekalign and P. Suneetha, 2012, Livelihood Activities, Challenges and Strategies at Participatory Forest Management Sub-catchment in Hararge High lands, Eastern Ethiopia, ABHINAV Journal, Vol 2, p$25-37$

Tsegaye. Gobeze et al, 2009. Participatory Forest Management and Its Impacts on Livelihoods and Forest Status: The Case of Bonga Forest in Ethiopia. International Forestry Review 11 (3): 346-358

West Hararge ARDO, 2003, Different report, chiro

Winberg, 2010, Participatory Forest Management in Ethiopia, Practices and Experiences, Addis Ababa: Food and Agriculture Organization, Sub regional office for Eastern Africa (SFE)

Yamane, t, 1967, Statics: an introductory analysis, PP, 886-887

Yemiru, T, 2011, Participatory Forest Management for Sustainable Livelihoods in the Bale Mountains, Southern Ethiopia, Unpublished PhD thesis, Swedish University of Agricultural Sciences, Uppsala 